\title{
NOTES
}

\section{Proposed Numbering Scheme for Mycobacterial Serotypes by Agglutination}

\author{
EMANUEL WOLINSKY and WERNER B. SCHAEFER \\ Metropolitan General Hospital, Cleveland, Ohio, and National Jewish Hospital, Denver, Colorado
}

\begin{abstract}
A new scheme is proposed for Schaefer's seroagglutination types of mycobacterial strains. In place of numbers and proper names and segregation into three species, Mycobacterium avium, $M$. intracellulare, and $M$. scrofulaceum, arabic numbers are assigned in order under the heading " $M$. avium Complex." For those species with but one or two recognized serotypes, the suggested designation is the species name followed by the term "serotype" followed by an arabic number if more than one type can be identified. It is proposed that a "clearing registry" be established within the framework of the International Working Group on Mycobacterial Taxonomy to prevent different authors from proposing the same serotype numbers for different serotypes.
\end{abstract}

The scheme proposed by Schaefer (4) for the recognition and classification of certain mycobacterial strains by agglutination with specific rabbit antisera has been a great help in identification and in taxonomic and epidemiologic studies, especially of those strains included in the species Mycobacterium avium, $M$. intracellulare and $M$. scrofulaceum (2-6). Recently, however, concern has been expressed by some investigators regarding three aspects of this system.

First, the scheme now consists of a mixture of Arabic numerals, Roman numerals, and proper names and is therefore awkward. Second, the addition of new serotypes would be difficult with the present jumble of numbers and names. Third, there is doubt and uncertainty about the clear-cut separation of the species $M$. avium, $M$. intracellulare, and $M$. scrofulaceum. Some $M$. intracellulare strains, especially those belonging to serotypes Davis, Watson, III, IV, V, and VI, possess virulence for chickens. In addition, strains of these six serotypes were sufficiently distinctive by the differential sensitin test so that Meissner and her colleagues (1) termed them an "intermediate group" between $M$. avium and $M$. intracellulare. Biochemically, these two species are similar. Also, many mycobacterial strains that can be classified as $M$. scrofulaceum on the basis of pigment characteristics and biochemical reactions agglutinate as one of the "intracellulare" serotypes. An example is the Watson strain, which is one of the reference strains of the Watson serotype.

The proposed new scheme is a compromise reached after extensive correspondence and meetings principally among the members of the International Working Group on Mycobacterial Taxonomy (IWGMT) and the Tuberculosis Panel of the Unites States-Japan Cooperative Medical Science Program. The grouping of the types into three separate species is abandoned in favor of the designation " $M$. avium complex," and 20 numbers in the scheme are reserved after the former $M$. intracellulare group for possible new types related to this group or to $M$. avium. The designations for $M$. scrofulaceum strains start with 41 , and those for $M$. gordonae strains will start with 51. A few types for the rather heterogeneous $M$. gordonae strains already have been recognized (E. Wolinsky and T. K. Rynearson, Unpublished data), and others probably will be added in the future.

Serotypes of several other mycobacterial species ( $M$. kansasii, $M$. marinum, $M$. gastri, $M$. fortuitum, $M$. chelonei, and $M$. szulgai) at present are restricted to one or two, and these will be designated by the species name followed 
by the term "serotype" followed by an arabic number if more than one type can be identified. The proposed scheme is shown in Table 1.

It is suggested that a small committee be constituted, perhaps within the IWGMT, to act

TABLE 1. Proposed scheme for serotyping several mycobacterial species

\begin{tabular}{l|l|c}
\hline \multicolumn{1}{c|}{ Species } & $\begin{array}{c}\text { Old serotype } \\
\text { designations }\end{array}$ & $\begin{array}{c}\text { New serotype } \\
\text { designations } \\
\text { M. avium } \\
\text { complex }\end{array}$ \\
\hline M. avium & $1,2,3$ & $1,2,3$ \\
$M$. intracellulare & IV & 4 \\
& V & 5 \\
& VI & 6 \\
& VII & 7 \\
& Davis & 8 \\
& Watson & 9 \\
& IIIa & 10 \\
& IIIb & 11 \\
& Howell & 12 \\
& Chance & 13 \\
& Boone & 14 \\
& Dent & 15 \\
& Yandle & 16 \\
& Wilson & 17 \\
& Altman & 18 \\
& Darden & 19 \\
& Arnold & 20 \\
& Scrofulaceum & 41 \\
& Lunning & 42 \\
& Gause & 43 \\
\hline
\end{tabular}

as a "clearing registry" for new proposals of mycobacterial serotype numbers. This would prevent any confusion arising by two different authors proposing the same serotype number for different serotypes.

\section{REPRINT REQUESTS}

Address requests for reprints to: Dr. Emanuel Wolinsky, Metropolitan General Hospital, 3395 Scranton Rd., Cleveland, Ohio 44109.

\section{LITERATURE CITED}

1. Anz, W., D. Lauterbach, G. Meissner, and I. Willers. 1970. Vergleich von sensitin-testen an meerschweinchen mit serotyp und hühnervirulenz bei $\mathrm{M}$. aviumund $M$. intracellulare-stammen. Zentralbl. Bakteriol. Infektionskr. I. Abt Original 215:536549.

2. Marks, J., P. A. Jenkins, and W. B. Schaefer. 1969. Identification and incidence of a third type of Mycobacterium avium. Tubercle 50:394-395.

3. Reznikov, M. 1970. Serologically identical "Battey" mycobacteria from lesions in a herd of pigs. Aust. Vet. J. 46:239-240.

4. Schaefer, W. B. 1965. Serologic identification and classification of the atypical mycobacteria by their agglutination. Amer. Rev. Resp. Dis. 92:85-93.

5. Schaefer, W. B. 1967. Serologic identification of the atypical mycobacteria and its value in epidemiologic studies. Amer. Rev. Resp. Dis. 96:115-118.

6. Schaefer, W. B. 1968. Incidence of the serotypes of Mycobacterium avium and atypical mycobacteria in human and animal diseases. Am. Rev. Resp. Dis. 97:18-23. 